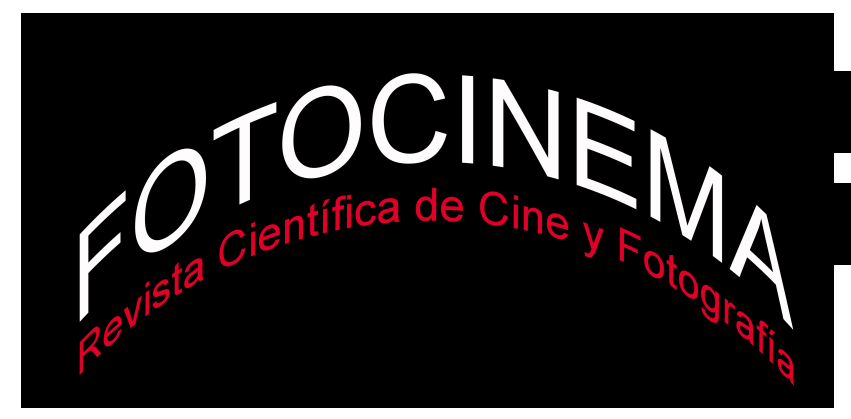

\title{
Belleza e irrealidad en la nueva pornografía feminista: la imagen pornográfica de Erika Lust
}

\section{Beauty and unreality in the new feminist porn: the pornographic image of Erika Lust}

\author{
Álvaro Martín Sanz \\ Universidad Carlos III de Madrid, España \\ Universitat Oberta de Catalunya, España \\ alvaromartinsanz@uoc.edu
}

\section{Resumen:}

Este artículo examina el cine pornográfico feminista realizado por la directora sueca Erika Lust. Un cine pionero que surge como rechazo de la heteronormatividad presente en el cine pornográfico tradicional, acusado de reflejar únicamente las excluyentes fantasías del varón. Este nuevo cine feminista es caracterizado por construir narrativas que van más allá del mero acto sexual, mostrando distintos tipos de sexualidades, y dando protagonismo a la mujer como sujeto activo. Un cine que también se caracteriza por una búsqueda estética constante a través de diversos recursos cinematográficos con el fin de crear una obra bella. A partir del estudio de los rasgos estilísticos de la serie de cortometrajes $X$-Confessions de Lust, se cuestiona el contenido de este tipo de obras, las cuales, a pesar de estar bien realizadas en términos cinematográficos, se quedan lejos de lograr su objetivo de ofrecer un retrato natural del sexo, al acabar implementando una nueva fantasía que nace como resultado de la búsqueda constante de belleza. Todo ello en oposición al fenómeno del cine amateur o gonzo, verdadero documental del acto sexual que no requiere de ninguna ficción, aunque pueda incorporarla, para elaborar su discurso de naturalidad y mostrar su objeto pornográfico.

\section{Abstract:}

This article examines the feminist pornographic films made by the Swedish director Erika Lust. A pioneering cinema that emerges as a rejection of the heteronormativity present in traditional pornographic cinema, accused of reflecting only exclusive male fantasies. This new feminist cinema is characterized by constructing narratives that go beyond mere sexual act, showing different types of sexualities, and giving prominence to the woman as an active subject. A cinema that is also characterized by a constant aesthetic search through various cinematographic resources in order to create a beautiful work. From the study of the stylistic features of Lust's series of short films $X$-Confessions, the content of this type of films is questioned, because despite being well made in cinematographic terms, are far from achieving its objective of offering a natural portrait of sex. Ending up in implementing a new fantasy as a result of the constant search for beauty. All of this in opposition to the phenomenon of the amateur or gonzo cinema, true documentary of the sexual act that does not require of any fiction, although it may contain it, to elaborate its discourse of naturalness and to show its pornographic object.

\section{Palabras clave:}

Pornografía; feminismo; porno; Erika Lust; heteronormatividad; pov.

Keywords:

Pornography; feminism; porn; Erika Lust; heteronormativity sex; pov. 


\section{Breve introducción al Postporno}

Parece imposible negar que las últimas tres décadas han traído toda una proliferación de estudios de género centrados en resolver de manera definitiva la cuestión del género y las distintas sexualidades contemporáneas. Fenómeno que se complementa con el de toda una creación académica de nuevas teorías feministas posestructuralistas que no tardan en conceptualizarse y difundirse lejos de su ámbito de creación y discusión gracias a la inmediatez de las redes sociales ${ }^{1}$. Teorías todas ellas que construyen en oposición a un concepto de dominación patriarcal omnipresente, que, si bien no siempre es definido bajo los mismos parámetros, siempre está basado en una heteronormatividad en las que la sexualidad es definida de manera única y excluyente. Lo que debiera sorprendernos, sin embargo, es que tanta cantidad de teoría, apenas haya tenido una correlación práctica dentro del audiovisual, medio por excelencia de la pornografía en la posmodernidad, principal vehículo ésta, de difusión del modelo de sexualidad tradicional. La emanación de las imágenes parece alejarse de cualquier discurso político, centrándose en la causa de su ser, el objeto pornográfico. $\mathrm{Y}$ es que realizando una labor arqueológica que se remonte a los inicios de la industria, cuesta trabajo cumplir con éxito la misión de encontrar una pornografía que trascienda su propio contenido con algún tipo de mensaje.

La figura de la exactriz y prostituta Annie Sprinkle bien podría ser uno de los primigenios elementos reivindicadores que surgen desde dentro de la industria para reivindicar el rol a menudo instrumental de la mujer en la misma. $\mathrm{Y}$ es que después de haber participado en cerca de mil películas decidió reconducir su carrera convirtiéndose en la última responsable de las obras promocionadas bajo su nombre. Inside Annie Sprinkle (Dentro de Annie Sprinkle, 1981), Rites of Passion (Ritos de Pasión, 1984) o Herstory of porn (Su historia del porno, 1999) son quizás algunos de sus títulos más emblemáticos. En ellos, bajo la premisa de que "la respuesta al porno malo

\footnotetext{
${ }^{1}$ Siendo El género en disputa: Feminismo y la subversión de la identidad (1990) de Judith Butler o An Ethics of sexual difference (1993) de Luce Irigaray algunos de los principales textos fundacionales del feminismo postmoderno.
} 
no es la prohibición del porno, sino hacer mejores películas porno" (Despentes, 2007, p. 73), Sprinkle se aleja de los estereotipos y las convenciones típicas del mundo pornográfico masculino para explorar inquietudes personales a modo de interrogantes, tales como la relación del sexo y el amor, del dolor con el placer, o del cuerpo con la ideología y carga social. Siempre con una cierta pretensión didáctica que hace de su pornografía una pornografía educativa que busca la liberación sexual de la mujer y la concienciación respecto a ciertas enfermedades de transmisión sexual como el SIDA. Planta así Sprinkle las semillas del postporno, movimiento artístico que comienza su difusión en torno a los años 2000 buscando bajo el lema del DIY (Do It Yourself) crear toda una nueva concepción pornográfica (Bourcier, 2017: 2). Construir todo un imaginario sexual en el que tengan cabida nuevas representaciones alternativas del cuerpo, mostrando así sexualidades que disten de la heteronormatividad que suele predominar en el porno convencional. En donde incluso la diferencia, cuando se manifiesta en una de sus múltiples formas (mostrando parejas lesbianas, poliamor, sexo entre personas con diferencias funcionales, étnicas o raciales) no es capaz de separarse de relaciones de control o humillación propias de lo heteronormativo.

Sin embargo, hasta muy recientemente, este postporno parecía quedar relegado a servir al arte de la performance y el happening. Destaca por ejemplo en nuestro país una prolífica creadora como Diana J. Torres, quien con su pornoterrorismo elabora una metáfora de una pornografía terrorista en la que lo agresivo, lo radical, lo grotesco y lo terrorífico son el vehículo desde el que atacar cuestiones como la violencia de género, la represión sexual o la homofobia (Torres, 2011). Partiendo siempre de una provocativa y violenta ruptura de cualquier tabú que tenga como objetivo lograr una liberación del propio cuerpo que sea universalizable con independencia del factor de género. Teniendo como fundamentos de base, al igual que en el caso de Sprinkle, el empoderamiento del propio cuerpo, el autoconocimiento por encima de prejuicios inculcados socialmente, y una sexualidad libre que busque el placer sin coacción o cohibición alguna. Y si bien como decimos, estos ejercicios son frecuentemente grabados en video para facilitar su 
distribución posterior, no es el audiovisual el canal de expresión fundamental que fomenta su concepción, por lo que difícilmente pueden considerarse estas piezas como obras cinematográficas por derecho propio. Otra relevante creadora es María Llopis, para quien

El postporno es la cristalización de las luchas gays y lesbianas de las últimas décadas, del movimiento queer, de la reivindicación de la prostitución dentro del feminismo, del postfeminismo y de todos los feminismos políticos transgresores, de la cultura punk anticapitalista y DIY (hazlo tú misma). Es la apropiación de un género, el de la representación explícita del sexo, que ha sido hasta ahora monopolizado por la industria. El postporno es una reflexión crítica sobre el discurso pornográfico. (Llopis, 2010, p. 38).

En parecidos términos lo señala el filósofo Paul B. Preciado cuando indica que "el postporno no es una estética, sino el conjunto de producciones experimentales que surgen de los movimientos de empoderamiento políticovisual de las minorías sexuales" siendo las producciones postporno "el archivo vivo de las sexualidades en resistencia frente al porno de Estado, el porno de papá y mamá, el porno colonial, el porno del cuerpo normalizado. Es la revuelta en la sala de montaje donde se construye el deseo" (Preciado, 2015). Pensamiento compartido por la teórica Rachele Borghi, para quien

le post-porn a pour objectif d'atteindre et de perturber les mécanismes de domination, y compris les mécanismes de la domination postcoloniale. La pratique post-porn peut en outre fonder une résistance "ordinaire“, en mettant l'accent sur les pratiques et la rupture avec un ordre imposé. ${ }^{2}$ (Borghi, 2013)

Lo cierto es que más allá de las reivindicaciones, el sistema de producción del cine pornográfico, al igual que sucede con el tradicional, desde sus inicios ha requerido de una serie de medios materiales que han impedido la proliferación de una mayor multiplicidad de voces creadoras. Quedando cualquier práctica feminista prácticamente reducida a la concepción subjetivada del propio trabajo que realizan dentro de los parámetros

\footnotetext{
${ }^{2}$ El objetivo de la post-pornografía es alcanzar y alterar los mecanismos de dominación, incluidos los mecanismos del gobierno poscolonial. La práctica postporno también puede generar una resistencia "ordinaria", poniendo el acento en las prácticas y en el orden impuesto.
} 
tradicionales determinadas actrices como la Sprinkle de la primera época, o Sasha Grey y Belladona más recientemente, cuyo trabajo es definido por la propia Llopis como "radicalmente feminista ya que en su representación de la mujer sexuada ésta es sujeto y no objeto" (Llopis, 2010, p. 32). Sin embargo, el fenómeno del cine independiente de guerrilla, nacido gracias al abaratamiento de los costes de producción, tiene su equivalente pornográfico en la infinita multiplicación de imágenes sexuales que proliferan en ciertas páginas contenedores de Internet que funcionan como abiertos receptores a nivel global, dispuestos a acoger cualquier video que un usuario cualquiera quiera compartir. Esta inmediatez audiovisual ha conseguido que cualquier sujeto sea susceptible de ser convertido en objeto pornográfico. Los actos de ver el elemento sexual, y el ser visto como tal se democratizan adquiriendo una nueva dimensión. Se expanden así las posibilidades de un tipo de cine que al no tener que servir a más justificaciones que las de crear un objeto erótico, parece no conocer límite alguno. Sin embargo, a pesar de toda esta multiplicidad, la heteronormatividad sigue funcionando como la regla principal dentro de la industria profesional. Es en este marco en el que surge esta nueva pornografía feminista de la cual la cineasta sueca afincada en Barcelona, Erika Lust, es uno de los principales exponentes.

\section{El cine de Erika Lust}

La pornografía de Lust es enunciada desde un primer momento como un manifiesto político ante una concepción errónea y estereotipada de la mujer, reacción activa ante un desencanto generalizado que reivindica además la sexualidad femenina como receptora de la imagen erótica, que puede sin prejuicios ser creada para ella como público principal. "No solo tenemos que aprender a disfrutar del sexo, tenemos que demandar nuestro derecho al placer sexual" (Lust, 2010, p. 7). Se trata de derrumbar la concepción de objeto sexual, de que la mujer tenga que estar en constante disposición de satisfacer el deseo y placer del otro, para pasar a reivindicar el propio cuerpo como sujeto que tiene derecho a disfrutar de su deseo y placer. Reconstruir un universo de fantasía desde una nueva óptica, crear nuevos paradigmas 
desde los que incluir la diferencia que hasta el momento ha sido rechazada sin que se haya ofrecido alternativa alguna. Se manifiesta abiertamente la necesidad de inclusión, de crear un nuevo producto, un producto en apariencia bello y natural que no esté sujeto a ninguna mentira $\mathrm{u}$ ofensa $\mathrm{y}$ que esté basado en el concepto de igualdad que define su ser. Acabar con clichés que permanecen invariables dentro del imaginario colectivo masculino y abrir el universo pornográfico a la diferencia, para que desde ahí pueda ser un objeto en el que distintas sexualidades, como es el caso de la femenina, puedan sentirse representadas.

Señala Roman Gubern que "catalogar al cine porno duro como documental fisiológico no constituye una exageración. El cine porno duro es, antes que nada, un documental fisiológico sobre la felación, el cunnilingus, la erección, el coito y la eyaculación” (Gubern, 2005, p. 27). Es este carácter el que le confiere a la pornografía un indudable valor didáctico en cuanto documento que retrata las posibilidades del acto sexual, es algo que no se puede obviar, se busca reivindicar esta nueva pornografía como herramienta educativa básica, sustituyéndola por todo un mundo de valores negativos que son transmitidos de manera indiscriminada y casi generalizante por el canal audiovisual, no necesariamente pornográfico, tal y como afirma la realizadora sueca:

Veo el porno como algo más que una pura herramienta de placer o excitación. Veo el porno como una herramienta de educación, de influencia, de política... porque al fin y al cabo es eso. El porno es un discurso. Un discurso que habla sobre sexualidad, que habla sobre femenino y masculino. Porque si tenemos un hombre y una mujer interactuando en una escena sexual, lo que hay es eso. Es una estructura, es una idea de cómo funciona el sexo. Y, sobre todo, cuando los jóvenes intentan entender cómo funciona el sexo... porque todos sabemos que los jóvenes usan el ordenador y la pornografía para aprender sobre sexo, porque es la única manera - bueno, las revistas también, pero hoy en día no hay tantas, más bien son imágenes en Internet-. Entonces son imágenes, fotos o vídeos en la red que muestran gráficamente cómo funciona esto del sexo. (Láser, 2017) 
Porque en el fondo, yendo a la esencia que se libera de cualquier adorno o consideración que se pueda decir acerca de ella, la labor pornográfica básica se basa en la encadenación de un conjunto de imágenes. Más sexuales o no, pero imágenes al fin y al cabo que se unen gracias a un sentido creador, el cual tiene la capacidad de autoreconocerse, trascendiendo toda mirada que se pose sobre él en su objetivo de definir una determinada intención. Sobran por lo tanto consideraciones externas, Lust se ve a sí misma como una realizadora dedicada a la explotación de un género determinado. De la misma manera que en el caso de una comedia o una película de terror, el cine es buen cine siempre y cuando cumpla su papel, su propósito. Y para Lust este objetivo de erotizar al espectador debe de ser universal, dirigido tanto a hombres como a mujeres, a las cuales considera se ha apartado demasiado tiempo de esta herramienta debido a las representaciones establecidas que presenta. La descalificación pre-visionado, únicamente basada en el contenido sexual de la película que se va a ver, no tiene entonces sentido. Mensaje que se dirige de manera intencionada y reivindicativa hacia la principal destinataria de su trabajo, la mujer: "No puedes decir que no te gustan las películas de adultos si nunca has visto nada más que una sola escena pornográfica” (Lust, 2010, p. 83). Es decir, una película debe ser valorada por encima de todo en base a su calidad, independientemente del contenido que posea, o citando a una de las influencias de la cineasta, la académica Linda Williams: "Las películas de arte hard-core pueden ser agresivas, violentas, humillantes, desesperadas, alineantes, tiernas, cariñosas, juguetonas, alegres, y por supuesto, aburridas. Pero son películas de arte que abarcan contenido sexual explícito” (Williams, 2008, p. 3). Valoración de la pornografía como cine, sujeta por lo tanto no solo a gustos personales, sino también a cierta objetividad estética y narrativa (cuando esta existe), punto en el que ambas mujeres coinciden en que la obra cinematográfica no puede ser discriminada en función del sexo que contiene. Dice la sueca literalmente:

I like to think of porn as just one more type of audiovisual entertainment, and I often compare it to other types of films, such as horror movies and comedies. Just as horror movies want to scare you to death, and comedies 
want to get you rolling in the aisle, porn wants to turn you on³. (Lust, 2010, p. 81)

Valoración de la pornografía como cine, sujeta por lo tanto no solo a gustos personales, sino también a cierta objetividad estética y narrativa (cuando esta existe), punto en el que ambas mujeres coinciden con Freixas y Bassa:

La obra cinematográfica no puede ser discriminada por razón de su sexo. Al final (y éste debería ser el principio), todo es cuestión de considerar objetivamente si hemos visto buenas o malas películas. Y no es más fácil ni más difícil que con cualquier otra ficción cinematográfica”. (Bassa, Freixas, 2000, p. 7)

Si bien es cierto que tal y como sostienen Barba y Montes, la esfera erótica es incompatible con la estética, y una imagen, o bien se toma como pornográfica con el erotismo y la excitación que ello conlleva, o bien evitamos el acontecimiento sexual y la tomamos como objeto estético. Ambos autores en La ceremonia del porno:

En tanto que mi excitación ante el acontecimiento pornográfico no se produzca, ese acontecimiento no es pornográfico, sino cómico, ridículo, inmoral, desagradable, o inocuo. Es muy habitual escuchar que la pornografía resulta "aburrida", "ridícula” o “inverosímil”. La respuesta más apropiada sería hacer comprender a quienes tal afirman que, sencillamente, lo que ha sucedido es que no han visto pornografía en absoluto [...] Y no la han visto, entre otras razones, porque como observadores han negado dos principios básicos para que el acontecimiento pornográfico se produzca: La conciencia prejudicativa de la revelación por un lado, y el compromiso de la excitación por el otro. (Barba, Montes, 2007, p. 44)

\section{X-Confessions: Confesiones de una mente calenturienta}

Lust trabaja desde el primer momento jugando con una concepción rompedora que sepa superar la banalidad en la que normalmente está

\footnotetext{
3 Me gusta pensar que el porno es solo un tipo más de entretenimiento audiovisual, y a menudo lo comparo con otros tipos de películas, como las películas de terror y las comedias. Así como las películas de terror quieren asustarte hasta la muerte, y las comedias quieren que te mueras de risa, la pornografía te quiere excitar.
} 
atrapada la pornografía. El objetivo de llegar a un nivel de resultado que considera lo suficientemente cinematográfico se convierte en un sugerente viaje en el que no solo no se niega el carnal propósito de la cinta, si no que habitualmente este es recubierto de algún sentimiento (sea del tipo que sea) que funciona como intensificador de las relaciones sexuales y sirve para provocar algo más allá de la excitación. Un sustrato que no arrebata la atención del sexo, sino que al contrario, carga a este de más sentido, bañando la pura fisicidad de los cuerpos en un componente erótico transgresor que es planteado en un primer momento y que normalmente se desarrolla a través de una sutil (que no entorpezca lo verdaderamente importante) línea narrativa centrada en la fantasía femenina. Obligatorio hablar aquí de una de una de las series más importantes y exitosas que ha desarrollado la sueca, las $X$-Confessions.

Proyecto, al igual que el resto de la obra de la realizadora, traído directamente del puro pensamiento ideológico que se cuestiona la validez de las representaciones actuales: ¿Tenemos la pornografía que queremos? ¿Refleja este porno nuestros deseos más secretos? ¿Nos sentimos identificados con él? ¿Existe una insalvable distancia entre el creador pornógrafo y el público? Lust concibe este trabajo como una incuestionable superación de todas estas preguntas al establecer un diálogo directo con el espectador. Haciendo un buen uso de las nuevas tecnologías, la realizadora se dirige a su comunidad de seguidores, labrada esta durante años gracias a su particular visión de la pornografía y formada mayoritariamente por mujeres (como es lógico), para pedir una confesión de su intimidad o fantasías en el formato de un pequeño texto que es publicado en una web con registro creada con este propósito. Desde su inicio Erika se comprometió a rodar pequeños cortometrajes a partir de estas ideas, a razón de uno o dos al mes, que aparte de estar accesibles bajo suscripción en la web, también son recopilados para su comercialización en DVD. Creando así un diálogo inaudito con el espectador, quién se siente valorado como consumidor al convertirse en la chispa inicial de inspiración erótica y sexual que prende la creatividad de una directora que se apropia de un contenido privado para 
darle forma y fondo, adaptándolo al medio con la función de que se transforme en una fantasía sexual colectiva.

Así pues, cada $X$-Confession lejos de ser una escena sexual aislada, constituye un pequeño hilo narrativo en el que el sexo hace acto de presencia. Esto, sumado a una mecánica de trabajo que huye de la repetición, tanto de actores, como de escenarios y típicas progresiones de la acción, es lo que diferencia cada una de las piezas de las corrientes glamcore más tradicionales. Y es que al contrario que otras empresas dedicadas a la producción de pornografía bella, alternativa y de corte femenino como Hegré-Art o $X-A R T$, la sueca es dueña de una rúbrica que confiere a su trabajo una definición más elaborada y menos industrial. Posee además su pornografía una fuerte inmediatez que no se centra en presentar a los protagonistas como objetos sexuales, sino como personajes cinematográficos. $\mathrm{Al}$ igual que en los mejores cortometrajes de ficción tradicional, Lust sabe dibujar el contexto de la historia en unos pocos planos, por lo que no necesita de explicaciones o presentaciones. De manera prácticamente instantánea sabemos quién son los personajes, en qué lugar se encuentran y qué es lo que va a suceder. Denota un control absoluto del medio, una técnica perfectamente pulida y certera que rara vez necesita de texto para guiarnos. Una puesta en escena tan directa que ayuda a que la historia no sea totalmente anónima, y a que por lo tanto podamos conocer a los personajes e identificarnos con ellos, sin que ese hecho obligue a que tengamos que esperar al motivo por el que estamos viendo su obra, el sexo.

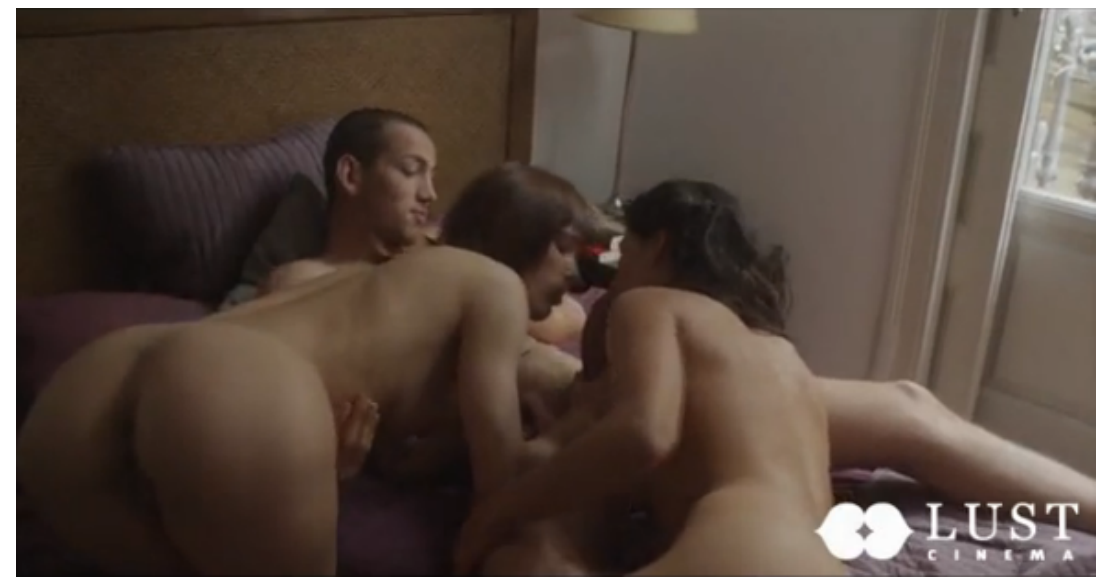

F1. Fotograma de We Know You are Watching, X-Confessions realizado por Lust. 
Es en esta narrativa en donde mejor se pueden apreciar los detalles de su manifiesto feminista, porque en el fondo el interés reside, más allá del sexo, en el papel activo que ostenta la mujer en las relaciones de poder muestra. Alejándose de la pornografía predominante, no hay en sus cintas hombres que puedan copular sin siquiera tener que comprobar si existe el deseo femenino de hacerlo ante una siempre apriorística disposición sexual por parte de sus compañeras. Al contrario, aquí es normalmente la mujer la que acostumbra a poseer la iniciativa sexual. Incluso en los retratos $B D S M$ más extremos en los que ésta participa, queda claro en la introducción de la pieza que quiere jugar al juego bajo unas normas acordadas. Retrato que define y reivindica la figura de la mujer liberada de la modernidad. Pero no se trata de dignificar a ésta a costa del hombre, al contrario, éste también queda en noble posición al no quedar su cuerpo reducido a su miembro sexual. Lust se preocupa de grabar el sexo como una globalidad más que de grabar un despiece de miembros. Huye de mostrar primeros planos de penetraciones o planos detalle descontextualizados y arrebatados de su sentido general salvo que sea con denotaciones exclusivamente poéticas, tal y como hace en la lírica y exótica $A$ night in Japan (Lust, 2014), en la que el elemento pornográfico es disuelto en distintos recursos cinematográficos. Lo erótico es el todo, la química de los actores, sus caras, sus gemidos y la conexión que mantienen más allá de sus órganos genitales. Se retrotrae de esta manera a los inicios de la pornografía, en dónde la principal preocupación no era tanto filmar a la mujer como rodar el acto sexual. Al ser preguntada en una entrevista el motivo de por qué no utiliza el típico plano ginecológico del que abusa el porno convencional, ella responde:

Yo trabajo alrededor de los actores y eso significa que no quiero que ellos me intenten plantear los planos, porque ellos lo hacen para que tú veas absolutamente todo. Porque ellos saben qué se busca en el porno. Pero como yo no busco eso, es mi trabajo el encontrar algo. Pero no me interesan particularmente los planos ginecológicos. No es algo que intente evitar, pero tampoco lo busco. Lo veo más como algo natural. Si muestras el sexo, pues es explícito ¿no? Se ven cosas, pero no lo ves todo. [...] Y luego también hay otra cosa que nos gusta a las mujeres, que es que buscamos al hombre. Que se vea 
el hombre, que se vean sus expresiones, que se vea su cara, que se vean sus brazos, que se vea su culo... Que se vea el cuerpo del hombre como persona y no solo como polla. Porque el porno masculino tiende mucho a que solo veas a la mujer, porque es ella la que te seduce. Y del hombre solo ves su polla. (Láser, 2017)

Continuando el análisis de qué hace especial a las obras de Lust, es trivial mencionar el cuidado y la elegancia con los que se trata a la propia imagen fílmica. Entrando en el tema de la plasticidad, la belleza fotográfica es algo que destaca en todos y cada uno de los planos que componen sus obras, encuadres bien planificados, a menudo simétricos, y un uso preciso de paletas de colores. Características estas, que unidas a la etiqueta de feminista, fomentan el rechazo de los seguidores de un tipo de un porno más tradicional, quienes ven una conexión directa entre la estética que luce una obra y su nivel de intensidad. Nada más lejos de la realidad que tachar al cine de Lust como soft-core por el cuidado uso de la imagen. El sexo aquí es siempre explícito, variando en intensidad desde el juego erótico suave hasta el hard-core más extremo sin que por ello se renuncie a una determinada concepción estética. Es decir, no solo no se niega el carnal propósito de la cinta, sino que se busca acentuar una belleza y unas maneras que sean válidas por sí mismas, independientemente de su contenido. Idolatrar la imagen, crear una armonía que merece ser valorada como objeto artístico a pesar de su evidente función pornográfica. Trabajando así hasta el mínimo detalle cada aspecto de la producción: cuidadas iluminaciones, tiempos medidos con calma y estilo, planificaciones trabajadas, texturas sonoras adecuadas y elegantes puestas en escena en las que incluso puede haber espacio para la innovación formal, tal y como es el caso de los créditos de inicio de la pieza The Art of Spanking (Lust, 2014).

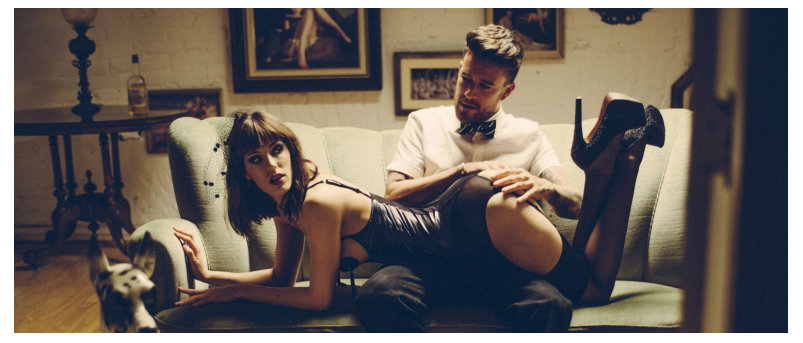

F2. Fotograma de The Art of Spanking, X-Confessions realizado por Lust. 
Atrevimientos estilísticos dentro de un género de sobra delimitado y definido que corroboran toda una declaración de intenciones por parte de un trabajo autoral que busca una reivindicación múltiple: la autoral como sujeto creador, la pornográfica como género perfectamente válido dentro del espectro cinematográfico, y la femenina como pretensión de igualdad y reconocimiento. De nuevo, dice la propia Lust al respecto:

El cine es una herramienta muy poderosa para transmitir valores, sensaciones y emociones, y creo que justamente en el género de porno está muy mal usado. Hoy en día ni siquiera se hacen películas, son vídeos hechos de cualquier manera. $\mathrm{Y}$ este es otro de los puntos donde yo diferencio mi cine del porno tradicional. A mí me gusta mucho el cine, quiero que tenga sentido y belleza, que sea estético y bonito, que esté bien iluminado, que haya una historia, que haya un desarrollo de personajes y que puedas entender quiénes son... iporque están ahí! Creo que esto es algo que comparto con muchas mujeres y también con algunos hombres, queremos un porno donde no es suficiente ver el sexo, queremos un poquito más de ayuda a nivel de storytelling. (Láser, 2017)

Reivindicación del cine pornográfico como cine, que como tal puede ser enseñado y perfeccionado gracias a una serie de técnicas y concepciones implícitas al género. Let's make a porno (2013), libro escrito por Lust en el que explora las distintas etapas de la creación de una obra pornográfica de una manera que no dista en absoluto del tratamiento que este tipo de manuales suelen dar a otra clase de audiovisuales con una consideración más noble, como el cine de ficción tradicional, el documental o el videoclip. Clara filosofía de creación de una autora que a pesar de todo está anclada en una industria que se mueve bajo ciertos patrones fijos que hasta la fecha parecen inamovibles. Sin ir más lejos, el formato que utiliza, ese en el que se basan sus $X$-Confessions, los pequeños cortometrajes de cópulas sexuales que no mantienen ninguna conexión entre sí, se asemeja bastante al estándar extendido en el mundo del porno a día de hoy. Pequeños clips de video que se dedican a retratar escenas sexuales de manera individual: un video, un conjunto de intérpretes y una escena sexual. Triunfo de la inmediatez de la era del consumo audiovisual. Sabemos lo que vamos a ver con tan solo ver un frame extraído del video. 
Atrás quedan épocas más ambiciosas (y de mayor presupuesto) en las que se desarrollaban verdaderas películas, largometrajes de 100-120 minutos de duración con una trama en la mayoría de los casos carente de interés más allá del funcionar como engranaje entre los distintos actos sexuales. La pornografía, la independiente también, parece haber quedado encerrada en su esencia original, en donde la de la sueca destaca por su retorno a ciertas nociones de narratividad, las cuales no escapan aun así de los típicos fetiches que dominan el mercado y que funcionan desde una misma concepción para atraer a distintos tipos de público. Y es que el contenido acaba siendo el mismo que se categoriza en las principales webs pornográficas: Couple, bondage, amateur, voyeur, footfetish, oral sex, milf, threesome, sex at work, orgy, y un larguísimo etcétera que parece calificar de manera inevitable el resultado en cada temática. A pesar de ello Lust trata de huir de lugares comunes, centrándose en historias que contengan un cierto elemento extraño-erótico que al contrario que en el porno convencional, plantee una situación erotizante antes incluso de que llegue el momento explícitamente sexual, jugando a transgredir la cotidianeidad con cierta ternura, picardía y a veces incluso humor, tal y como sucede en la pieza titulada: $A$ blowjob is always a great last-minute gift idea! (Lust, 2013). Así pues, al contrario que en el caso de la pornografía tradicional, no se busca constantemente la excitación del espectador segmentando la narrativa con contenido explícito, se confía en cambio en que el material es lo suficientemente sugestivo como para que esta llegue sin ser forzada.

En cuanto a temáticas exploradas, destaca una toda recreación de la cotidianidad erotizada, en la que cualquier momento es susceptible de romper el último resorte y devenir en desenfrenada pasión sexual. Fruto sin duda del fantaseo de la mente colectiva que le proporciona estas imágenes a través del apartado de su web. Cualquier lugar puede ser un lugar en el que liberar la pasión, cualquier individuo es susceptible de llegar a ser la compañía perfecta con la que alcanzar el orgasmo. Hecho por otro lado reivindicado desde siempre por la pornografía tradicional y sus arquetípicas figuras de fontanero, pizzero, o madre soltera o viuda. Sin embargo, aquí la invitación a la cópula rara vez nace del instante, parece venir más bien de una 
tensión sexual acumulada en el tiempo y no resuelta todavía. Y en esos casos en los que aparece como instantánea lo hace de una manera magnética y por encima de todo recíproca, natural juego de igual a igual al que le suelen sobrar palabras, la atracción no se comunica verbalmente. Momentos que surgen con espontaneidad cuando un curioso voyeur es descubierto o quedan claras las intenciones que guarda un continuado cruce de miradas en la biblioteca, tal y como sucede en la pieza Do you find my feet suckable? (Lust, 2014) protagonizada por la hasta hace no mucho tiempo omnipresente Amarna Miller. Circunstancias perfectas para jugar con el poder de la imaginación y de la fantasía onírica en la que sus confesiones se basan. La plausibilidad de cada hecho se mezcla con el deseo de su posible realización en un escenario cotidiano que otorga tintes costumbristas. La imaginación se calienta ante esa situación que se fantasea en la cabeza pero que no siempre logra materializarse en la realidad. Con cierto sadismo en más de una ocasión da Lust una pequeña estocada a sus personajes, volviéndolos a fijar después del acto sexual en una realidad que necesitan manipular en función de sus pasiones. Podría haber pasado, podría pasar, deseo que pase... Desvaríos que permiten salir de la cotidianeidad del sexo corriente hacia fantasías puramente pornográficas tales como la persecución, la dominación, la sumisión o el voyerismo, para goce eso sí del espectador.

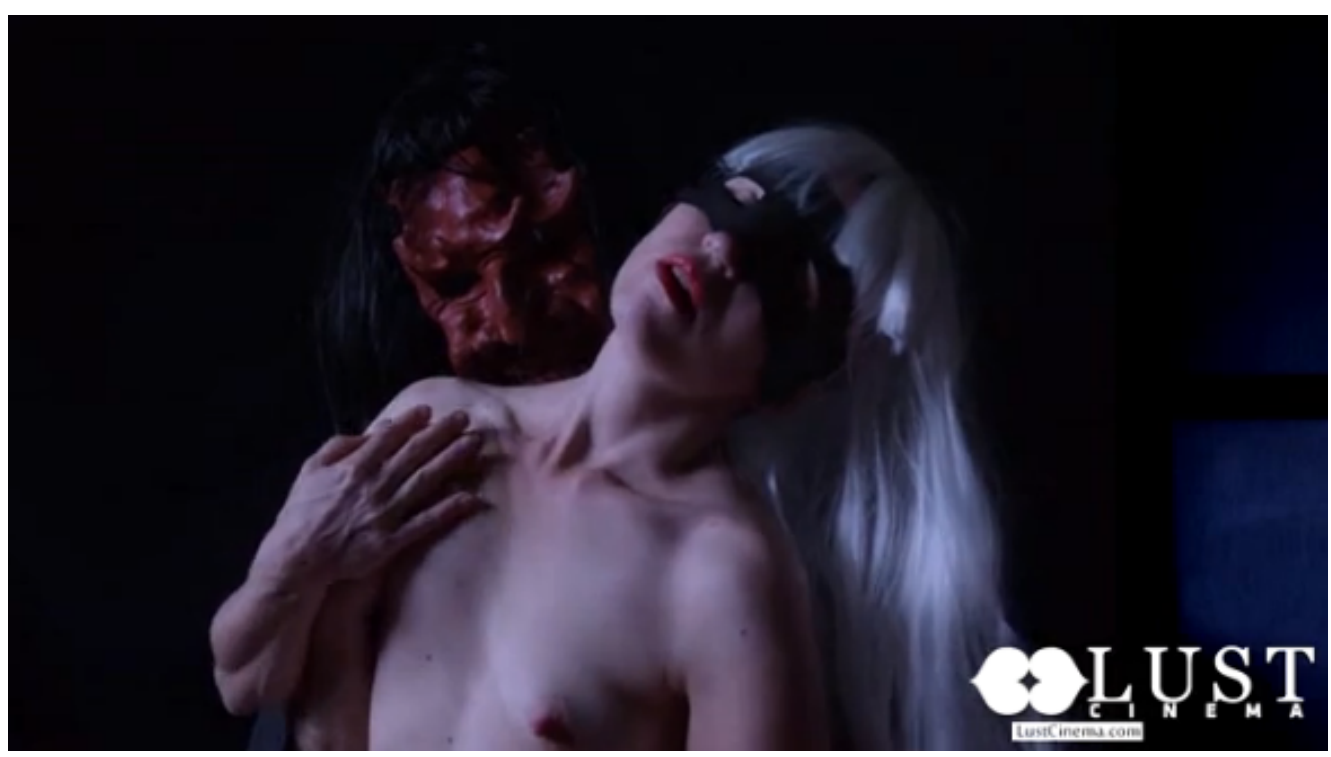

F.3 Fotograma de A night in Japan, X-Confession realizado por Lust. 


\section{Reconstrucción y falsedad de la realidad pornográfica}

Y es que a pesar de que la pornografía sea por definición el ámbito de la fantasía erótica, algo interesante cabría decir acerca de este tipo de cine de corte feminista que surge como reacción a la falsedad, a los prejuicios y a la heteronormatividad del "cine de hombres", dirigido este fundamentalmente a un público masculino heterosexual y formado por estereotipos de género tradicionales que conforman una serie de relaciones de poder y sumisión en donde el consumidor (repetimos, hombre, blanco y heterosexual) es el rey. Lo cierto es que cuanto más cinematográficas y perfectas son las secuencias que componen el cine de Erika Lust, más se alejan de la esfera de lo real, adentrándose en un camino que las mantiene a distancia de las antiestéticas imágenes producidas por el documentalismo amateur para acercarlas a una esfera más elevada que las delimita como imágenes artísticas por encima de su contenido sexual.

El problema, si es que puede ser considerado como tal, es que el preciosismo que exhiben hace que se caiga incoherentemente en el error que motivó su creación, la falsedad que posee la imagen pornográfica tradicional. Reconstruyendo una realidad edulcorada y fantasiosa en donde prime la visión de la directora. Lust se cuida de no caer en una falsa reconstrucción marcada por la visión masculina en la que la mujer sea un objeto de libre disposición, formando parte de orden desequilibrado en el que siguiendo a Laura Mulvey el placer de mirar se escinde entre un masculino activo como portador de la mirada y un femenino pasivo que es observado (Mulvey, 2001, p. 370).

Pensamiento diametralmente opuesto al reduccionismo de Román Gubern (en el año 89), quién lejos de entrar a valorar los estereotipos y roles fijados que presenta la pornografía heteronormativa, afirma que el hecho de que esta sea únicamente funcional para el sexo masculino tiene que ver "con la mayor excitabilidad erótica visual del hombre en relación con la mujer [...] según una diferencia basada en sus roles biológicos." (Gubern, 2005, p. 18) Simple argumento que reduce para todo un género la pornografía a un carácter didáctico motivado por la curiosidad: 
El interés de la pornografía masculina para la espectadora femenina radicaría en que es contemplada como curiosidad y como eventual escuela, para comparar sus cuerpos y sus técnicas en relación consigo misma y con su propia pareja. (Gubern, 2005, p. 16)

Reduccionista justificación biológica que aparta cualquier otra explicación por considerarla innecesaria en vez de ahondar en la complejidad de la realidad social, la cual podría demostrarnos que ese supuesto desinterés de la mujer hacia la pornografía vendría más bien de una mezcla de ciertos modelos de comportamiento propios del sistema patriarcal que son inculcados a través de una determinada educación de la que se siguen unos roles relacionados con la castidad y la pureza, cercanos a la virtud y alejados de la corporalidad carnal, tal y como sostiene el pensador francés Pierre Bordieu en su obra La dominación Masculina (2014) en la que, compartiendo la posición de Laura Mulvey, arremete contra el condicionamiento que supone nacer bajo el papel femenino.

Así pues, la directora sueca se centra en evitar los aspectos ideológicos que considera nocivos dentro de la pornografía predominante. Pero en esta búsqueda de un nuevo erotismo pornográfico descuida por exceso el aspecto fundamental de la reconstrucción, el atractivo de la naturalidad. Primando una belleza en la puesta en escena y una armonía generada conscientemente en la que a pesar de no mostrar cuerpos arquetípicos, acaba reinando en su lugar la seductora singularidad de los personajes. El cine de Erika Lust es extremadamente estético, y es precisamente esa cualidad la que lo convierte en sumamente irreal. Supone toda una fantasiosa recreación desde cero, atractivo de caras jóvenes, peinados, iluminación, y maquillaje, opuesta al paradigma del género gonzo, también llamado normalmente primera persona o POV4. Técnica predominante hoy en día influenciada por la pornografía amateur, a la que a menudo buscando realismo trata de imitar, en la que el actor masculino es el que se encarga de grabar el coito, colocando al espectador en su lugar y dotando a la escena de más fuerza y verosimilitud que si la cámara permaneciera ajena a la acción limitándose a registrar lo que acontece.

4. Siglas en Ingles: Point of View. Punto de vista. 
El objetivo de Lust de crear una pornografía bella en cada momento, parece enfrentarse con el de construir una herramienta educativa verídica. Y es que los modelos que se crean, permanecen en una esfera completamente estética poseedora de una belleza extrema que nos es presentada como falsa e idealizada, y aunque ambientada en ella, alejada en todo momento de la vida cotidiana real. Fantasías contemporáneas que parecen estar demasiado preparadas para el consumidor que busca la esencia que proporciona lo inmediato. En frente se erige la sinceridad del porno convencional, que al amparo de las nuevas tecnologías y las nuevas formas de consumo que han traído, parece haber olvidado de forma consciente el juego ficcional en el que solía moverse. La simpleza es la clave, y la excitación es lo primero, el único fin. Objetivo sencillo alejado de los discursos ideológicos que plantean las principales corrientes postporno. Con este fin en mente, no es necesario falsear el contexto o crear una ficción de la nada si ésta no es demandada por los consumidores que, acostumbrados a la sociedad de la inmediatez, cada vez quieren llegar a la esencia del documento antes. Los actores no son presentados como individuos normales anclados a una determinada situación, al contrario, son presentados como sí mismos. No es necesario crear ningún tipo de papel porque el erotismo está contenido en la misma esencia de la cópula.

La interpretación se reduce por lo tanto a avivar y magnificar el mero acto sexual. En el que además parecen haberse girado las tornas. En una nueva concepción, la mujer ya no es ese objeto sexual disponible de forma constante para satisfacer las necesidades del hombre. En su lugar se ha convertido en un objeto de adoración hacia el que se crea la obligación de anteponer la donación de placer antes que la búsqueda del propio. Solo comprendiendo esto puede explicarse la obligatoriedad que supone en la actualidad la filmación del cunnilingus, presente en la gran mayoría de videos, así como la proliferación del squirting, gracias a actrices capaces de lograr la tan codiciada eyaculación femenina, demostración objetiva del orgasmo femenino que a través de la expulsión de fluidos queda tan probada como el masculino. El placer del hombre, su masculinidad, ya no parece 
venir del hecho de la propia fornicación en sí, si no de su propia transformación en funcional instrumento de goce.

Este neorrealismo del sexo está por encima de todo basado en el estilo directo, naturalista y sin cortes que caracteriza al género gonzo. En el que incluso para remarcar la identificación con el espectador no es infrecuente que la mujer mire y se dirija al objetivo de la cámara (transgrediendo así una de las normas fundamentales del cine de ficción tradicional) con el fin de provocar una reacción directa en el consumidor. Sencillo truco que forma parte de un estilo que implica una realización más fácil, rápida y barata que una producción tradicional, que en palabras del productor estrella José María Ponze "ha limitado completamente el lenguaje del porno. Sobre todo porque se ha masificado" (Costa, 2006, p. 105). Ya que la inmediatez en la creación de contenidos parece primar sobre la calidad de los mismos, el amateurismo y los videos caseros, como imágenes pornográficas reales y directas que son, parecen haberse convertido gracias a su frescura y facilidad de producción, y siempre por medio de la técnica gonzo, en el objeto a seguir por toda la industria.

La propia Lust realiza una reflexión sobre este método de producción en uno de sus $X$-Confessions más anómalos de los realizados hasta la fecha, Lets make a porno (Lust, 2013). Obra en la que busca fusionar ambos ámbitos, por un lado su cuidada propuesta estética y por el otro el amateurismo más radical e inocente. Para ello elige a una pareja virgen delante de las cámaras cuya confesión de fantasía erótica es precisamente la grabación de un vídeo pornográfico. La realizadora divide entonces la escena en dos universos cercanos pero irreconciliables, tanto en tratamiento como en narrativa: por un lado, la pareja que retoza en la cama, y por el otro, con un carácter metapornográfico, la escena que está teniendo lugar alrededor de la filmación, en donde técnicos, cámaras, y la propia Erika incluida no apartan la mirada del proceso de grabación. Extrañeza que es mostrada con un montaje paralelo que alterna entre ambas realidades, creando un reconocimiento no al sexo como tal, sino a la pornografía que lo retrata. 
En cuanto a la estética de los protagonistas, siguiendo con el realismo que plantea el gonzo, la pornografía heteronormativa tradicional huye ahora de estereotipos clásicos cuando lo considera necesario, tanto en el caso del hombre como en el de la mujer. En la posición masculina, lejos de usar el arquetipo de hombre musculado y bronceado, la imperfección física, mostrada por medio de actores en absoluto modelos, refuerza la identificación con el voyeur, el cual tiene una barrera menos que derribar para convertirse en el sujeto protagonista de la acción sexual. En el caso de la mujer por el contrario se trata de alejar el ideal de belleza femenina para reforzar la credibilidad de la fantasía. Se evitan cuerpos de topmodel, se busca una normalidad física sin operar salida de la cotidianeidad. Por encima de todo, se reivindican las cualidades atractivas que posee cada cuerpo, olvidando el paradigma de que la mujer es un objeto sexual en función de la perfección de todo un físico. Ahora, en cambio lo es únicamente en función de algunos atributos, como pueden ser una cara bonita, unos senos grandes o un culo firme, en ocasiones incluso lo es por el mero hecho de ser mujer. Así es como se llega a la conversión en objeto sexual de absolutamente cualquier mujer, sin importar su sexo, edad o color. Al igual que en los videos amateur cualquier persona es susceptible de ser transformada en objeto pornográfico. En frente queda el cine de Lust, que si bien también huye de los patrones tradicionales que el porno ha mantenido durante tanto tiempo, en su búsqueda de crear un producto bello, no puede renunciar a mostrar cuerpos jóvenes y a menudo atléticos. Pues, aunque se busque un ideal de belleza alternativo, con actores con peinados extravagantes, tatuajes o piercings, la imposición de una estética agradable siempre está presente.

\section{Conclusiones}

A través de sus X-Confessions Erika Lust busca crear una nueva pornografía de contenido esencialmente feminista. Partiendo del mensaje crítico de las corrientes postporno para enfrentarse a la heteronormatividad del cine pornográfico tradicional al considerar sus representaciones falsas e irreales, y desarrollando un tipo de cine caracterizado por una mayor igualdad entre 
sexos y un mayor cuidado de la imagen. Sin embargo, esta búsqueda de crear un producto bello por encima de todo, lastra el principal propósito, el de crear una imagen verídica que represente la realidad, para en su lugar, ofrecer debido a sus cuidados acabados, una ensoñación fantasiosa que a todos los niveles no acaba distando tanto de las irrealidades que presentaba el cine pornográfico heteronormativo tradicional al que quiere superar. Se rechazan por ejemplo cuerpos siliconados o extremadamente musculosos por considerarse prueba de la falsedad presente en el porno tradicional, sin embargo, se reduce la sexualidad a una sexualidad estética con cuerpos bellos y jóvenes. Al contrario de lo que hace la pornografía heteronormativa actual, para la que cualquier individuo es en potencia un objeto sexual.

El contraste entre ambos tipos de cine es mayor si consideramos el hecho de que el cine pornográfico mainstream de hoy en día, entendido como heteronormativo e influenciado por el amateurismo, se ha abierto hacia un desarrollo del estilo gonzo o documental. Prescindiendo de recrear cualquier situación narrativa previa al coito para en su lugar centrar todo su interés en documentar el acto sexual, sin ningún artificio, preparación, o corte de plano. Los $X$-Confessions de Erika Lust por lo tanto surgen como reacción a un tipo de cine que ya no es el predominante, que ha evolucionado en la realidad contemporánea debido a que los nuevos medios técnicos permiten que cualquiera pueda crear un objeto pornográfico. Y por ello mismo, no logran reflejar la realidad, conformándose con efectuar una reconstrucción pornográfica desde una perspectiva feminista reivindicativa que lejos de su propósito nunca va a poder ser totalmente inclusiva, debido a que forma un sistema de ficción en un momento en el que el consumo mayoritario demanda contenidos documentales. Es el amateurismo la principal fuente de este tipo de videos, un campo que va más allá de la pornografía tradicional heteronormativa y de la de Lust, al abrirse a todo tipo de sexualidades, tantas como sujetos creadores haya. Es aquí y sólo aquí en donde la pornografía feminista puede librarse de cualquier tipo de directriz, y plasmar una mirada propia del sujeto. La misión de las X-Confessions de plasmar en video una fantasía femenina no tiene por lo tanto necesidad de ser en los casos en los que la escena que quiere filmarse destaca por su accesibilidad. Dado el hecho 
de que los propios sujetos que demandan estas piezas son capaces de crear su propia pornografía sin necesidad de intermediarios, logrando además un registro fidedigno de la realidad al documentarla directamente y no necesitando por lo tanto una reconstrucción artificial de la forma en que se les presenta, vendida como un producto bello, estético y perfecto.

\section{Referencias bibliográficas}

Bassa, J. y Freixas, R. (2000). El sexo en el cine y el cine de sexo. Barcelona: Paidós Ibérica.

Barba, M. y Andrés, J. (2007). La ceremonia del porno. Barcelona: Anagrama.

Bordieu, P. (2014). La dominación masculina. Barcelona: Anagrama.

Bourcier, S. (2017). Protest porn et néolibéralisme : la politique explicite de la post-pornographie. Théorème 28. Représentations-limites des corps sexuels dans le cinéma et l'audiovisuel contemporains. París : Presses Sorbonne Nouvelle.

Borghi, R. (2013). Post-porn. Rue Descartes. 2013/3 (n $\left.{ }^{0} 79\right)$ (pp.29-41) https://www.cairn.info/revue-rue-descartes-2013-3-page29.htm\#no1 DOI : 10.3917/rdes.079.0029

Butler, J. (1990). El género en disputa: El feminismo y la subversión de la identidad. Barcelona: Paidós Ibérica.

Costa, J. (2006). El sexo que habla: el porno español explicado por sí mismo. Madrid: Aguilar.

Despentes, V. (2007). Teoría King Kong. Santa Cruz de Tenerife: Melusina.

Irigaray, L. (1993). An ethics of sexual difference.United States of America: Cornell University Press.

Gubern, R. (2005). La imagen pornográfica y otras patologías de la imagen. Barcelona: Anagrama

Láser, V. y Jonas, G. (11/12/2012). Lust: "veo el porno como una herramienta de educación". Jot Down Magazine. Recuperado de http://www.jotdown.es/2012/11/erika-lust-veo-el-porno-como-unaherramienta-de-educacion-de-influencia-de-politica/ [04/07/2018]

Llopis, M. (2010). El postporno era eso. Santa Cruz de Tenerife: Melusina.

Lust, E. (2010). Good Porn. A woman's guide. Berkeley: Seal Press.

Lust, E. (2013). Let's make a porno. Barcelona: Erika Lust

Mulvey, L. (2001). Placer visual y cine narrativo. En W. Brian (Ed.), Arte después de la modernidad. Nuevos planteamientos en torno a la representación. (pp. 365-377). Madrid: Ediciones Akal. 
Preciado, P. B. (18/4/2015). Activismo postporno. El Mundo. Recuperado de<http://www.elmundo.es/cultura/2015/04/18/552e788222601da6 2d8b458c.html > [04/07/2018]

Torres, D. J. (2011) Pornoterrorismo. Pamplona: Txalaparta.

Williams, L. (2008). Hard-Core Art Film: The Contemporary Realm of the Senses. Barcelona: Quadern portátil Volumen 13. Museu d'art Contemporani de Barcelona. 